\title{
Aproximación a la situación de los escribanos de cabildo en la provincia de Málaga a mediados del Setecientos español: ¿una mala organización laboral o desidia profesional?
}

\author{
Lorena Barco Cebrián ${ }^{1}$
}

Recibido: 28 de noviembre de 2016 / Aceptado: 10 de mayo de 2017

Resumen. El escribano de cabildo es una figura bastante conocida por la historiografía española, sin embargo, su análisis adolece de una falta de estudios para el siglo XVIII español en general y para la provincia malagueña en particular. De ahí que nuestro objetivo sea acometer su estudio y análisis para el período cronológico aducido, y para el territorio geográfico malagueño. El estudio se basa en fuentes archivísticas pertenecientes a diferentes archivos tanto nacionales como locales, donde hemos podido constatar la presencia de estos fedatarios y cuál fue su papel a lo largo de la horquilla cronológica propuesta. A través de la investigación hemos podido comprobar que el escribano concejil fue una figura importante dentro del cabildo municipal, ya que su principal función era la de dejar constancia escrituraria de todo lo que pasaba en la urbe. Esta labor primordial de este colectivo socio-profesional en numerosas ocasiones no era completada, ya que se ha podido evidenciar una cierta desidia profesional por parte de estos fedatarios. Son numerosas las quejas presentadas ante el cabildo por la falta de implicación de estos profesionales, al mismo tiempo que también son numerosos los documentos que carecían de cualquier valor legal por la falta de rúbrica de estos escribanos. Todo ello nos indica que se trataba de un colectivo que gozaba de una gran falta de organización en la realización de sus quehaceres profesionales.

Palabras clave. Escribano de cabildo; siglo XVIII; Málaga; desidia profesional.

\section{[en] Approximation to the situation of the clerks of council in the province of Malaga in the Spanish mid-seventeenth: a poor professional organization or professional sloth?}

Abstract. The notary of chapter is a figure known enough by the Spanish historiography, however, its analysis suffers from a lack of studies for the Spanish eighteenth century in general and for the Malaga province especially. The study is based on original sources belonging to different files. Across the investigation, we could have verified that these notaries were an important figure within the town council, since its main function was to leave a scriptural record of everything that happened in the city. This primordial work of this socio-professional collective in many occasions was not completed, since it has been possible to verify a certain professional indifference on the part of these notaries. There are numerous complaints filed before the town council for the lack of involvement of these professionals, while there are also numerous documents that lacked any legal value due to the lack of rubric of these

1 Universidad de Málaga (España)

E-mail: lbarco@uma.es 
notaries. All this indicates to us that it was a collective that enjoyed a great lack of organization in the accomplishment of its professional tasks.

Keywords. Clerk of chapter; 18th century; Málaga; professional indifference.

Sumario. 1. Introducción. 2. El escribano de cabildo o ayuntamiento en Málaga: definición y quehaceres desde su instauración hasta el siglo XVIII. 3. Los escribanos de cabildo en la provincia malacitana a mediados de la centuria Ilustrada: ¿mala praxis o desidia profesional? 4. Conclusión. 5. Apéndice documental.

Cómo citar: L. Barco Cebrián, “Aproximación a la situación de los escribanos de cabildo en la provincia de Málaga a mediados del Setecientos español: ¿una mala organización laboral o desidia profesional?", Documenta \& Instrumenta, 16 (2018), pp. 41-60. 


\section{Introducción}

El escribano de cabildo o ayuntamiento ha sido una figura bastante analizada por la historiografía española, sobre todo a partir de las últimas décadas del siglo pasado ${ }^{2}$. Sin embargo, no todas las entidades territoriales han sido analizadas, y tampoco todas las épocas se han acometido de forma equitativa. Así, para Andalucía en general y para la provincia malagueña en particular, la figura del escribano o fedatario de cabildo ha sido más estudiada en la transición de la Edad Media a la Edad Moderna y en los inicios de esta última ${ }^{3}$. No obstante, el siglo XVIII ${ }^{4}$ adolece aún de una falta

2 A. ALVAR EZQUERRA, E. GARCÍA GUERRA, T. PRIETO PALOMO, J. C. ZOFIO LLORENTE, L. ZOZAYA Y MONTES, "Los escribanos del Concejo de Madrid (1561-1598), en Cuadernos de historia de España, vol. 79, $n^{\circ}$ 1, Buenos Aires, enero/diciembre 2005, pp. 167-202.

H. CABALLERO CAMPOS, "El poder de la pluma en el mundo hispánico. Un estudio aproximativo a los escribanos públicos de gobernación y cabildo en la provincia del Paraguay (s. XVIII)", en BRAVO J. J., BERNAL CASTILLERO, M. A. (et al.), Aportaciones a la historiografia del mundo hispánico: trabajos de investigación del II Máster de Historia del Mundo Hispánico, 2005, pp. 37-59.

F. CARRERA DÍAZ YBARGÜEN, "El escribano municipal según una información enviada al consejo de Castilla el año 1626: requisitos legales para ejercer el oficio", en Boletín del Instituto de Estudios Asturianos, Año $\mathrm{n}^{\mathrm{o}} .44, \mathrm{n}^{\mathrm{o}} .133,1990, \mathrm{pp} .45-72$.

E. CORRAL GARCÍA, El Escribano de Concejo en la Corona de Castilla (siglos XI al XVII), Excmo. Ayuntamiento de Burgos, Burgos, 1987.

A. CASTILLO GÓMEZ, "Cultura escrita y actividad escribanil en el Siglo de Oro", en VILLALBA PÉREZ, E.; TORNÉ, D., (ed. lit.), El nervio de la república: el oficio de escribano en el Siglo de Oro, 2010, pp. 351370 .

V. M. CUÑAT CISCAR, "Los escribanos y notarios públicos por el rey y los escribanos del concejo de las Cuatro Villas de la Costa de la Mar de Castilla en el siglo XVI", en L. BARCO CEBRIÁN; A. MARCHANT RIVERA (coords.), "Dicebamus hesterna die..." estudios en homenaje a los profesores Pedro J. Arroyal Espigares y M. Teresa Martín Palma, Encasa, Málaga, 2016, pp. 164-197.

G. F. FERNÁNDEZ SUÁREZ, "Una primera aproximación a los escribanos del concejo de Lugo entre los siglos XVI y XVIII”, en BALIÑAS PÉREZ, C; FERNÁNDEZ SUÁREZ, G. F. (coords.), Sub Urbem: Historia, sociedade e cultura da cidade: Actas do VII Curso de Primavera, Facultade de Humanidades de Lugo, 3-6 de maio de 2011, 2012, pp. 143-159.

M. C. GARCÍA BERNAL, "Las escribanías de Cabildo de Guadalajara: ¿un oficio devaluado o revalorizado? (1700-1760)", en GARCÍA BERNAL, M. C.; OLIVERO GUIDOBONO, S. (coords.): El municipio indiano: relaciones interétnicas, económicas y sociales: homenaje a Luis Navarro Garcia, 2009, pp. 127-150.

M. D. ROJAS VACA, "Los escribanos de Concejo de Cádiz (1557-1607), en Historia, Instituciones, Documentos, $\mathrm{n}^{\circ} .24,1992$, Publicaciones de la Universidad de Sevilla, Sevilla, pp. 429-448.

P. YBÁÑEZ WORGOYS, "Los Escribanos Mayores del Concejo Malagueño (1516-1556)", en Baética. Estudios de Arte, Geografia e Historia, no. 23, 2001, pp. 615-626.

3 P. J. ARROYAL ESPIGARES, Las escribanías públicas de Málaga (1487-1516), Málaga: Departamento de Prehistoria y Ciencias de la Antigüedad y Edad Media de la Universidad de Málaga, Málaga, 1991.

P. J. ARROYAL ESPIGARES, M. E. CRUCES BLANCO, M. T. MARTÍN PALMA, El Notariado en Málaga durante la Edad Moderna. Estructura Organizativa, Servicio de Publicaciones Universidad de Málaga, Studia Malacitana, Málaga, 2007

P. J. ARROYAL ESPIGARES; M. T. MARTÍN PALMA, "Escribanos y notarios en las villas de la jurisdicción de Málaga”, en MORENO TRUJILlo, M. A.; OBRA SIERRA, J. M. de la; OSORIO PÉREZ, M. J., El Notariado Andaluz: Institución, práctica notarial y archivos. Siglo XVI, II Jornadas sobre el Notariado en Andalucía, Granada, 22 a 24 de abril de 2011, Granda, 2011, pp. 39-64.

P. J. ARROYAL ESPIGARES, M. T. MARTÍN PALMA, M. E. CRUCES BLANCO, "Sobre los orígenes de la institución notarial en Málaga”, en PARDO RODRÍGUEZ, Ma. J., OSTOS SALCEDO, P. (coords.), El notariado andaluz en el tránsito de la Edad Media a la Edad Moderna: I Jornadas Sobre el Notariado en Andalucía, del 23 al 25 de febrero de 1994, 1995, pp. 47-74.

A. MARCHANT RIVERA, Los escribanos públicos en Málaga bajo el reinado de Carlos I. Servicio de Publicaciones Universidad de Málaga, Studia Malacitana, Málaga, 2002.

4 Como ya apuntara el catedrático Ángel Riesco Terrero en su trabajo. 
de literatura científica que analice la institución notarial española en su globalidad, al mismo tiempo que tampoco existe una bibliografía extensa para la provincia malacitana 5 .

Por todo lo aducido, proponemos en este trabajo y en las sucesivas páginas, analizar de forma incipiente la figura del escribano de cabildo para la provincia malagueña. La horquilla cronológica utilizada ha sido la primera mitad del siglo XVIII. Esto es debido a que en este período cronológico tuvo lugar una importante fuente documental que nos sirve para situar a este colectivo socio-profesional. Nos referimos al denominado como Catastro de Ensenada, fuente original que reproduce como ninguna otra de la época la sociedad española de la centuria Ilustrada. Al mismo

R. CÓZAR GUTIÉRREZ, "De lo que yo el infraescripto doy fe: los escribanos de la villa de Albacete durante el siglo XVIII", en Revista de historia moderna: Anales de la Universidad de Alicante, nº. 8, 2010, pp. 269299.

L. ESCUDERO ESCUDERO, "Los escribanos manchegos a mediados del siglo XVIII. Una aproximación a su patrimonio agrario", en PÉREZ ÁLVAREZ, Ma. J.; MARTÍN GARCÍA, A. (coords.), Campo y campesinos en la España Moderna; culturas políticas en el mundo hispano, Vol. 2, 2012, pp. 1337-1347.

M. A. EXTREMERA EXTREMERA, “Adquisición y transmisión de oficios de escribano público en Córdoba (siglos XVII-XIX). Actas del III Congreso de Historia de Andalucía, Córdoba, 2001. Historia Moderna. Tomo II, Caja Sur, Córdoba, 2003, pp. 113-122.

M. A. EXTREMERA EXTREMERA, "El delito en el archivo. De escribanos, falseadores y otras gentes de mal vivir en la Castilla del Antiguo Régimen", en Hispania, LXV/2, n. 220, 2005, pp. 465-484.

M. A. EXTREMERA EXTREMERA, El Notariado en la España Moderna. Los escribanos públicos de Córdoba (siglos XVI-XIX), Calambur, Madrid, 2009.

M. A. EXTREMERA EXTREMERA, "Escribanos, cultura escrita y sociedad en la España Moderna (siglos XVI-XVIII)", en Litterae: cuadernos sobre cultura escrita, nº. 3-4, 2003-2004, pp. 187-206.

G. F. FERNÁNDEZ SUÁREZ, "Una primera aproximación a los escribanos del concejo de Lugo entre los siglos XVI y XVIII”, en BALIÑAS PÉREZ, C; FERNÁNDEZ SUÁREZ, G. F. (coords.), Sub Urbem: Historia, sociedade e cultura da cidade: Actas do VII Curso de Primavera, Facultade de Humanidades de Lugo, 3-6 de maio de 2011, 2012, pp. 143-159.

D. GONZÁLEZ CRUZ, Escribanos y notarios en Huelva durante el Antiguo Régimen (1701-1800) (La historia onubense en sus protocolos notariales), Universidad de Sevilla-Vicerrectorado de los Centros Universitarios de Huelva, Huelva, 1991.

M. LÓPEZ DÍAZ, "Una aproximación a la institución notarial en Santiago: escribanos y notarios a mediados del siglo XVIII", en Estudios mindonienses: Anuario de estudios histórico-teológicos de la diócesis de Modoñedo-Ferrol, $\mathrm{n}^{\circ} .8,1992$, pp. 421-456.

A. MARCHANT RIVERA, "Los escribanos españoles del siglo XVIII a la luz de la literatura de viajes: viaje por España de Joseph Townsend", en Baética. Estudios de Arte, Geografia e Historia, n. 28, 2006, pp. 325335.

5 P. J. ARROYAL ESPIGARES, "Nómina de notarios, escribanos y oficiales de pluma en Andalucía a mediados del siglo XVIII, según el Catastro de Ensenada", en http://riuma.uma.es/xmlui/handle/10630/4860?show=full L. BARCO CEBRIÁN, "La Institución notarial de la provincia malagueña según el Catastro de Ensenada: estado de la cuestión y primeros resultados", en Isla de Arriarán: revista cultural y cientifica, 40-41 (2013-2014), pp. 39-74.

L. BARCO CEBRIÁN; A. MARCHANT RIVERA, "La fe pública en la provincia de Málaga a mediados del siglo XVIII", en I. CARRASCO CANTOS (ed. lit.), Aportaciones al estudio del español del siglo XVIII, Comares, Granada, 2015, pp. 97-118.

M. E. CRUCES BLANCO, "Escribanos y escribanías en la provincia de Málaga (1496-1905)", en Inventario de la documentación notarial conservada en el Archivo Histórico Provincial de Málaga, 1496-1905, 2008 (2 edición), pp. 1-16.

J. ESCALANTE JIMÉNEZ, Los escribanos en Antequera. Un análisis global: (1475-1869), Tesis Doctoral dirigida por el Dr. Juan Jesús Bravo Caro, Málaga, 2015.

M. REDER GADOW, "Breve estudio sobre los escribanos públicos malagueños a comienzos del siglo XVIII", en Baética: Estudios de arte, geografia e historia, nº. 5, 1982, pp. 195-205.

A. SÁNCHEZ MAIRENA, "Escribanías públicas y del concejo de Marbella (Málaga) y su jurisdicción entre los siglos XV y XVIII”, en VILLALBA PÉREZ, E.; TORNÉ, E. (eds.), El nervio de la república: el oficio de escribano en el Siglo de Oro, 2010, pp. 119-143. 
tiempo, también se han utilizado y consultado fuentes originales pertenecientes a archivos locales, que nos dan y cumplimentan una información muy valiosa para acercarnos a la figura del escribano de ayuntamiento.

\section{El escribano de cabildo o ayuntamiento en Málaga: definición y quehaceres desde su instauración hasta el siglo XVIII}

Los escribanos, tanto los castellanos como los aragoneses, tenían una doble función; por un lado, revestían de fe pública todas las escrituras de la vida judicial privada de todos aquellos que pasaban ante ellos; y, por otro lado, estaban obligados a atender los asuntos municipales, siempre que el cabildo lo requiriese, además de atender a la justicia $^{6}$. Por lo tanto, todo escribano, ya fuera de una categoría u otra, es decir, numerarios, concejiles, reales, etc., tenían una serie de obligaciones pero también muchos beneficios nada desdeñables a los ojos del común.

En cuanto a sus obligaciones estaban las de redactar todos aquellos documentos en los que quedaran registrados los actos que ante ellos pasaren. Además, debían de asentar todos los documentos en una serie de libros, en el caso de los escribanos públicos hablamos de los denominados como protocolos notariales; en el caso de los escribanos de cabildo estos debían llevar y registrar muchos más, todos ellos reflejo de la vida de la propia ciudad, tal y como ya hacía referencia de ellos Corral García en su obra, así nos encontramos con libros de registro, de ordenanzas, cartas, cédulas, provisiones, privilegios, escrituras y sentencias, depósitos, registros de entrada, bienes del concejo, libro de cabildos o actas capitulares, libro de infracciones, e incluso un libro de inventario del archivo ${ }^{7}$. Aunque estas fueran las tipologías de libros que debía registrar un escribano de cabildo, lo cierto es que muchos de ellos no asentarían ni registrarían sus quehaceres en todos, careciendo muchas veces de algunos de estos libros. Ya sea por desidia en los quehaceres del propio escribano, ya sea porque con el paso del tiempo estos han desaparecido, lo cierto es que no tenemos constancia de muchos de ellos para la provincia malagueña. Algunos de estos libros ya eran de obligado cumplimiento cuando se publicaron las ordenanzas municipales de Málaga quedando recogidas algunas de las mencionadas tipologías:

(...) que el dicho escriuano del Concejo tenga libro en que esten y se assienten todos los traslados de cartas y mandamientos de sus Magestades e las pressentaciones de ellas y de los autos que passaren cerca de lo concerniente a ellas el qual dicho libro sea cosido y enquadernado con sus coberturas de pergamino. Iten que el dicho escriuano tenga otro libro en que ponga las condiciones y ordenanças que la ciudad tiene fechas con que arriendan y mandan arrendar las rentas de sus propios e otras rentas, en el qual assimismo ayan de assentar y assienten los autos de los arrendamientos (...)

Otrosi que el escriuano del Concejo tenga un libro donde assiente la pressentacion de los dos veedores que cada un officio y officiales de la dicha ciudad (...)

6 A. MARCHANT RIVERA, "Los escribanos españoles del siglo XVIII a la luz de la literatura de viajes: viaje por España de Joseph Townsend”, en Baética. Estudios de Arte, Geografia e Historia, 28 (2006), p. 327.

E. CORRAL GARCÍA, Ob. Cit., pp. 68-69. 
Iten que el dicho escriuano del concejo sea obligado a tener otro libro en que este assentado la relacion de las tiendas e possesiones que la dicha ciudad tiene y en que personas estan rematadas e por que tiempos y precios $(\ldots)^{8}$.

Iten el dicho escriuano de Concejo a de tener otro libro enquadernado donde se assiente particularmente las cedulas o prouisiones que su Magestad diere para pasar pan o otras cosas por el puerto y playa de esta dicha ciudad, y las presentaciones que de ellas se hizieren en el dicho Cabildo y el obedecimiento y autos que sobre ello passaren $(. . .)^{9}$.

Iten que el dicho escriuano sea obligado a tener otro libro enquadernado donde se assiente el cargo de pan e marauedis que se entregare al depositario del posito de la dicha ciudad en el qual se le a de hazer cargo y descargo de lo que reciuiere y pagare o uendiere (...)

Iten a de tener otro libro enquadernado en el qual se an de assentar todas las denunciaçiones que se hizieren en el dicho oficio asi de campo como de la ciudad y las condenaciones que se hallaren y pertenecieren a los propios de la dicha ciudad (...)

Iten el dicho escriuano a de tener otro libro en que se asiente el cargo de los marauedis que recibiere y entraren en poder del mayordomo de los propios de la dicha ciudad (...)

Iten otro libro donde se asienten las sentencias que tiene Malaga en su fauor y los pleytos que trata, y ante quien penden, y quien son los escriuanos de la causa $(\ldots)^{10}$.

Además de llevar estos libros o registrar en ellos las diferentes actuaciones de la ciudad, los escribanos de cabildo tenían una serie de funciones algo diferentes a las del escribano público, aunque en última instancia este también lo fuera. En estos casos, las del escribano de cabildo, concejo o ayuntamiento, iban acorde a las propias de las labores del cabildo, y por ello, se asemejan mucho a lo que hoy denominamos por secretario, de ahí que algunos autores prefieran hablar de secretarios cuando se refieren a esta tipología de escribanos. El fedatario del concejo debía dar asesoramiento al cabildo o a algunos de sus miembros siempre que fuera requerido, igualmente daba fe pública administrativa, debía realizar la función notarial dentro del concejo, además de otras series de funciones judiciales, siempre relacionadas con el devenir de la ciudad y su cabildo ${ }^{11}$.

Por otro lado, las obligaciones de los escribanos quedaban recogidas en las ya mencionadas ordenanzas municipales. Las de Málaga fueron publicadas en 1611, y en ellas estaban consignadas todas las obligaciones que debían llevar a término estos escribanos, como ya hemos visto en el caso de los libros que debían registrar. A las ya mencionadas funciones cabe sumar para el escribano de ayuntamiento la de poseer una de las dos llaves de las puertas del dicho cabildo, una la tendría el portero y otra el mencionado escribano.

8 P. J. ARROYAL ESPIGARES; Ma T. MARTíN PALMA, Ordenanzas del Concejo de Málaga, Málaga, 1989, p. 29.

9 Ibídem, p. 30.

10 P. J. ARROYAL ESPIGARES; Ma T. MARTÍN PALMA, Ordenanzas del Concejo..., p. 31.

11 E. CORRAL GARCÍA, Ob. Cit., p. 44. 
El fedatario concejil también tenía la obligación de silenciar a aquellos asistentes al cabildo municipal que interrumpieran el buen devenir de la reunión, al mismo tiempo que entre sus funciones estaba la de tomar y asentar los votos en cualquier elección que se hiciera en el seno del cabildo, aunque él no tuviera ni voz ni voto en ningún caso ${ }^{12}$ :

(...) E si algunos estuuieren hablando unos con otros, el Escriuano del Cabildo les diga que callen e oygan a aquel qu esta en pie hablando, e no le estoruen ni empachen ${ }^{13}$...el escriuanos del Cabildo a de asentar el boto de cada uno segun que de la manera e por las palabras que lo dixere porque en el libro de Cabildo parezca si conuiniere el boto de cada uno para su cargo o descargo $(. . .)^{14}$.

Pero no todo eran obligaciones para el fedatario concejil, sino que este también gozaba de unos numerosos beneficios. Uno de ellos era el de tener un sitio señalado dentro del cabildo, cerca y próximo a todos los gobernantes de la ciudad, de donde nadie lo podía echar, además de poseer su propio armario para guardar sus cosas y papeles, que no fueran demasiado importantes para la ciudad, ya que siempre podían ser susceptibles de ser sustraídos. Así queda recogido en las ordenanzas malagueñas:

Ha de tener assi mismo el Escriuano de Cauildo su lugar señalado donde se assiente. E dondo estuuiere su assentamiento a de auer un armario muy bien ${ }^{15}$ hecho con su cerradura, donde pueda tener algunas escripturas manuales que no sean de mucha importancia, porque alguno no tenga osadia de los tomar, saluo cartas mensajeras e peticiones, y otras cosas semejantes $(\ldots)^{16}$.

Más importante quizás para el propio escribano era el percibir una serie de sueldos, dietas, quitaciones y raciones que le eran asignados por el propio monarca. Esta cantidad era fija, a diferencia de sus homólogos numerarios, era además anual ${ }^{17}$, derivada de los propios de la ciudad, al igual que para el resto de regidores y caballeros que integraban el concejo. Esta diferencia es significativa y ello explica la importancia que para los escribanos numerarios tenía el poder acceder a uno de estos dos escritorios concejiles de la capital malagueña. El hecho radica en que el fedatario público no tenía un salario fijo, por lo que sus beneficios dependían en cierto modo de su pericia o no a la hora de hacerse con una buena clientela que fuera más o menos fiel. Sin embargo, el escribano de cabildo, hiciera el trabajo que hiciera siempre recibiría un salario fijo anual, lo que daba más seguridad y estabilidad económica en

12 J. MARTÍNEZ GIJÓN, "Estudios sobre el oficio de escribano en Castilla durante la Edad Moderna", en Centenario de la Ley del Notariado. Junta de decanos de los colegios Notariales de España. Separata del volumen I, sección primera (estudios históricos), Madrid, 1964, p. 279.

13 P. J. ARROYAL ESPIGARES; Ma T. MARTÍN PALMA, Ordenanzas del Concejo..., p. 20.

14 Ibídem, p. 21.

15 Ibídem, p. 19.

16 P. J. ARROYAL ESPIGARES; M T. MARTÍN PALMA, Ordenanzas del Concejo..., p. 21.

$17 \quad \mathrm{M}^{\mathrm{a}}$ L. PARDO RODRÍGUEZ, Señores y escribanos. El notariado andaluz entre los siglos XIV y XVI, Secretariado de Publicaciones Universidad de Sevilla, Sevilla, 2002, p. 109. 
el hogar del escribano en cuestión. No obstante, no es menos cierto que existen numerosas quejas por parte de estos fedatarios concejiles por el impago de su salario por parte del cabildo, ya que si la ciudad no tenía dinero a causa de cualquier epidemia o acontecimiento catastrófico, los miembros del cabildo no podían percibir sus emolumentos.

Por otro lado, no debemos olvidar que los escribanos del concejo debían ser elegidos de entre uno de los fedatarios numerarios de la ciudad, villa o lugar, fuera quien fuera el que tenía la prerrogativa de su nombramiento, es decir, ya fuera el propio monarca, el propio cabildo, o algún señor ${ }^{18}$.

El oficio de fedatario concejil, en muchas ocasiones, tenía, al igual que sus homólogos numerarios, un carácter vitalicio. Aunque originariamente estos oficios estaban dentro de los denominados como cadañeros, es decir, que eran elegidos cada año, lo cierto es que se seguía produciendo ese nombramiento anual pero simplemente para confirmar al escribano que ya lo ejercía. Así, en pleno siglo XVIII las escribanías de cabildo también eran vitalicias en la capital malagueña y algunas de las ciudades y villas de la provincia, pero existía una diferencia con respecto a las escribanías numerarias. En oposición a estas últimas que quedaban insertas en los bienes del propio escribano, es decir, podía comprarlas, en el caso de las escribanías de cabildo estas quedaban insertas dentro de la propiedad de la ciudad o de algún noble o familia relevante. Por ello, generalmente, no podía quedar dentro de una misma familia a perpetuidad, así que ese carácter vitalicio podía ser revocado por varias causas. Una de ellas era el óbito del escribano, cuando este fallecía era la ciudad quien elegía a su sucesor. Otra de las causas podía ser que el escribano que la ejerciera incurriera en pena, en este caso se le vetaba del cargo y se nombraba a un nuevo escribano. Por último, existía una tercera causa, nos referimos a la propia renuncia del escribano en cuestión, el cual solía renunciar a su oficio sobre todo cuando estaba enfermo o imposibilitado y le era imposible ejercer convenientemente su oficio ${ }^{19}$.

Siguiendo con los beneficios de estos escribanos concejiles, otro de ellos era el de nombrar a sus propios oficiales, aquellos ayudantes que serían en la práctica los que realizaran el grueso del trabajo de las escribanías de cabildo. Esta prerrogativa les fue concedida a estos oficiales malagueños ya en el siglo $\mathrm{XVI}^{20}$.

Por otro lado, los escribanos, tanto numerarios como del concejo, junto con los maestros de primeras letras y los preceptores de gramática estaban exentos de realizar el servicio militar ${ }^{21}$. Este era uno de los grandes beneficios de los que gozaban estos oficiales liberales de la pluma, ya que así se guardaban las espaldas de morir de forma prematura, aunque esta fuera por el bien de la patria. Estos fedatarios también gozaban de un gran favor ya que tenían cierta inmunidad, esto se debía, como ya mencionara la profesora Marchant Rivera, a que nadie podía interponer querella alguna contra estos oficiales de pluma ${ }^{22}$ a no ser que fuera ante justicia de la ciudad:

\footnotetext{
E. CORRAL GARCÍA, Ob. Cit., p. 13.

M L. PARDO RODRÍGUEZ, Ob. Cit., p. 85.

P. YBÁÑEZ WORGOYS, Ob. Cit., p. 622.

M. J. PONCE RAMOS, El Cabildo Malagueño Durante el Reinado de Fernando VI, Servicio de Publicaciones Universidad de Málaga, Málaga, 1998, p. 70.

22 A. MARCHANT RIVERA, “Los escribanos españoles del siglo...”, p. 329.
} 
Iten los dichos escriuanos no rreçiban querella criminal de persona alguna, sy no fuere ante la justiçia de esta çiudad, ni den mandamiento para prender, si no fuere aviendo visto la dicha justiçia primero la ynformaçion e mandado que se dé mandamiento para prender ${ }^{23}$.

Como se puede observar tras este análisis de beneficios, prerrogativas e inmunidades de las que gozaban los escribanos de cabildo, este oficio era uno de los mejores situados dentro de la sociedad de las centurias que conforman la Modernidad. A diferencia de otros muchos ciudadanos, los fedatarios concejiles tenían un salario fijo anual; podían ejercer su oficio con ayuda de oficiales; pero, sobre todo, tenían relación directa con el poder gubernamental de la ciudad, convirtiéndose así en enlace entre los ciudadanos y los regidores de la urbe.

\section{Los escribanos de cabildo en la provincia malacitana a mediados de la centu- ria Ilustrada: ¿mala praxis o desidia profesional?}

Atendiendo a los escribanos de cabildo de la capital malagueña a lo largo de la centuria dieciochesca, hay que decir que fueron dos a lo largo de todo el siglo, y eran al mismo tiempo escribanos numerarios de la capital. El Concejo malagueño se reunía en las denominadas como casas consistoriales que se encontraban en la calle de San Sebastián, la que conocemos hoy como Compañía, teniendo que remodelarse precisamente a comienzos del siglo XVIII, concretamente en el año $1705^{24}$.

En el resto de ciudades, villas y lugares de la provincia, nos encontramos con un único escribano de cabildo en la mayoría de ellas -en cincuenta y uno de los lugares catastrados para las pesquisas de la Única Contribución-, y dos escribanos de cabildo en algunas de las villas y lugares con más peso social y económico de la provincia: Alhaurín el Grande, Álora, Cártama, y Coín, curiosamente las integrantes de las Cuatro Villas ${ }^{25}$. Hecho a destacar es que en las ciudades más importantes como lo eran Ronda y Antequera, que aun contando con mayor población y con un número más elevado de fedatarios públicos, tan solo queda registrado, según el Catastro de Ensenada, un único escribano concejil para cada una de ellas.

Sumando todas ellas en la provincia malagueña para los años centrales del Setecientos se constata la presencia de un total de 63 escribanías de cabildo, y no tienen su correlación en el número de escribanos del concejo, ya que un mismo fedatario podía ejercer varias escribanías de ayuntamiento, generalmente aquellas cuyas poblaciones eran de menor entidad. Así, el número de estos escribanos del concejo era

23 P. J. ARROYAL ESPIGARES; Ma T. MARTÍN PALMA, Ordenanzas del Concejo..., p. 33.

24 F. GUILLÉN ROBLES, Historia de Málaga y su provincia, Instituto de Cultura Diputación Provincial de Málaga, CSIC. Con prólogo de M. Rodríguez de Berlanga, Imprenta de Rubio y Cano, Málaga, 1874, p. 499.

25 Corregimiento de Málaga integrado por las villas de: Alhaurín el Grande, Álora y Pizarra, Cártama, Coín. Ver B. GARCÍA GUILLÉN, Coín y el Corregimiento de las Cuatro Villas de la Hoya de Málaga. Siglo XVII, tesis doctoral dirigida por los Dres. Ma Isabel Pérez de Colosía Rodríguez y Juan Jesús Bravo Caro, Málaga, 2009. 
de 51. Los fedatarios que aunaban en su persona más de un escritorio eran los siguientes: Marcos Joseph Domínguez era escribano de ayuntamiento de Churriana ${ }^{26}$ y de Alhaurín de la Torre ${ }^{27}$. Lucas Pastor lo era de Benadalid ${ }^{28}$ y Benalauría ${ }^{29}$. Pascual Dionsio Criado era escribano del concejo tanto de Benamargosa ${ }^{30}$ como de El Borge $^{31}$. Benamocarra ${ }^{32}$ e Iznate ${ }^{33}$ compartían el mismo escribano de cabildo, Juan Félix de Villaluenga. Vicente Palmero era, asimismo, el fedatario del concejo tanto de Benaoján ${ }^{34}$ como de Montejaque ${ }^{35}$. Benaque ${ }^{36}$ y Macharaviaya ${ }^{37}$ compartían a Francisco Antonio Coronado. Y, por último, Juan Basilio Pabón servía las escribanías de ayuntamiento de Sedella ${ }^{38}$ y Cómpeta ${ }^{39}$.

Como se puede apreciar, estos fedatarios de cabildo que servían varios escritorios a la vez, aunque bien es cierto que algunos de ellos eran también escribanos de $f e$ $\operatorname{chos}^{40}$ de alguna villa menor, servían esas escribanías en villas cercanas territorialmente, lo que les facilitaría su trabajo a la hora de desplazarse para realizar sus quehaceres. En estos casos de duplicidad de servicios escribaniles siempre el fedatario se dedicaría con mayor atención a una de las escribanías dejando de manera subsidiaria la labor en la otra. Generalmente atenderá de manera más asidua en aquellos lugares de mayor población o bien donde tenía fijada su residencia.

Los escribanos de cabildo mantenían una relación más estrecha entre ellos que los escribanos numerarios, de hecho, hay numerosas quejas por parte de ellos y de sus oficiales al propio concejo. Quejas en las que se muestran unidos y se dan síntomas de una especie de conciencia colectiva por parte de estos escribanos de ayuntamiento. En sesión capitular celebrada el día 18 de enero del año 1740 en la capital malagueña, los dos escribanos mayores, Antonio Calvo y Juan de Rute, presentan una instancia al cabildo para que se les pague lo que han trabajado en el año antecedente de 1739. No solo el trabajo ejecutado por ellos mismos sino también el efectuado por sus dos oficiales. A dichos oficiales se les pagaba la tercera parte, aunque sobre ellos recaía la mayor parte del trabajo que tenía lugar en el seno de las escribanías municipales ${ }^{41}$.

De las numerosas sesiones capitulares que se han analizado se deduce que los oficiales liberales del concejo, es decir, tanto los escribanos de cabildo como sus

\footnotetext{
A. G. S., Dirección General de Rentas, Catastro de Ensenada, Respuestas Generales, Libro 284, fs. 267r-v. Ibídem, Libro 276, fs. 789v y 818v.

Ibídem, Libro 278, f. 395r.

Ibídem, Libro 279 , fs. 2 v y 22 r.

Ibídem, Libro 279 , fs. 388v y $391 \mathrm{r}$.

Ibídem, Libro 279, fs. 437r-v.

Ibídem, Libro 278, fs. 364v y 380v.

Ibídem, Libro 292, fs. 274r-v.

Ibídem, Libro 279 , fs. $97 \mathrm{v}$ y $117 \mathrm{v}$.

Ibídem, Libro 296, fs. 196r y 206r-v.

Ibídem, Libro 279, fs. 680, 690v y 691v.

Ibídem, Libro 296, fs. 524v u 540r.

Ibídem, Libro 300, fs. 465v y 473r.

Ibídem, Libro 285, fs. 371r-372v.

40 L. BARCO CEBRIÁN, La institución notarial en Málaga a la luz del Catastro de Ensenada, Tesis Doctoral dirigida por la Dra. Alicia Marchant Rivera, Málaga, 2015, pp. 377-382.

41 A. M. M., AA. CC., Vol. 132, fs. 53r-v.
} 
oficiales, no eran eficientes con su trabajo y descuidaban sus quehaceres en numerosas ocasiones ${ }^{42}$. En sesión capitular del 15 de julio del año de 1740, los diputados encargados del archivo, los señores don Francisco Amat y don Francisco Camargo, expresan su malestar al cabildo porque los documentos que conforman dicho archivo no están ordenados, ni siquiera están encuadernados ni forrados, con el perjuicio que ello supone para su buena conservación. Cabe recordar que estos documentos eran de importancia capital no solo para los ciudadanos que presentaban cualquier asunto ante el concejo, sino para el devenir de la propia ciudad malagueña, ya que en ellos quedaba recogida toda la vida de la ciudad, sus privilegios, ordenanzas, quejas, etc. Era de vital importancia para el buen funcionamiento de ella que el archivo y sus documentos se custodiaran en las mejores condiciones posibles. Así los dos diputados del archivo piden al cabildo que se nombre a un oficial de vuena letra...para que se consiga el que todo lo que esta suelto tenga sus asientos ${ }^{43}$.

Esta misma desidia por parte de los escribanos de cabildo la hallamos de nuevo en el legajo que conforman las sesiones capitulares que tuvieron lugar al correr del año 1750. Comienzan estas actas con la sesión capitular celebrada el día 2 de enero del mismo año, y su inicio es una queja por parte del regidor y procurador general de la capital malacitana, don Francisco Camargo Mondragón. Pero el discurrir del acta es inusual, en ella se inserta el proceso mediante el cual se expresa el fallecimiento del escribano de cabildo Antonio Calvo, y que al sobrevenir esta muerte de forma inesperada el citado escribano concejil había dejado sin firmar y sin terminar numerosas de las escrituras y sesiones celebradas en el dicho año de 1750. Muchos acuerdos se encontraban sin la firma notarial, había borradores que no se habían pasado todavía a limpio, etc.; por ello, se le pide al cabildo que nombre a peritos expertos que puedan entender su letra y que validen estos documentos, ya que sin su validación nada de lo dicho en ellos tendría valor en un futuro, con el perjuicio consiguiente para el derecho no solo de la propia ciudad sino de todos aquellos vecinos que hubieran recurrido a ella en el período señalado. La ciudad nombra para ello a dos escribanos numerarios de la ciudad, Dionisio López Cuartero y Hermenegildo Ruiz, para que ejecuten el reconocimiento de las escrituras de Antonio Calvo. Este examen lo terminaron en julio del año 1751 Hermenegildo Ruiz, y en agosto del mismo año, Dionisio López Cuartero ${ }^{44}$. Hay que decir que el volumen que integra el año 1750, su inicio, se realizó en realidad en 1751, cuando ya había fallecido Antonio Calvo, y tuvieron que llevarse a cabo las pesquisas señaladas.

En la siguiente imagen podemos apreciar una de las páginas del acta capitular a la que acabamos de hacer referencia, se puede ver cómo no son válidas estas escrituras ya que están tachadas, y además se destila la fisionomía que debía tener un borrador, donde el escribano aprovechaba cualquier espacio en blanco para realizar cuentas y demás anotaciones que nada tenían que ver con las escrituras que componían el legajo final.

42 Mala praxis ya apuntada para los escribanos de corte por E. VILLALBA, "Sospechosos en la verdad de lo que pasa ante ellos. Los escribanos de la corte en el Siglo de Oro: sus impericias, errores y vicios", en Litterae. Cuadernos sobre Cultura Escrita, $\mathrm{n}^{\circ}$. 2, 2002, pp. 121-149.

43 A. M. M., AA. CC., Vol. 132, fs. 409r-v.

44 A. M. M., AA. CC., Vol. 141, fs. 1r-4r. 


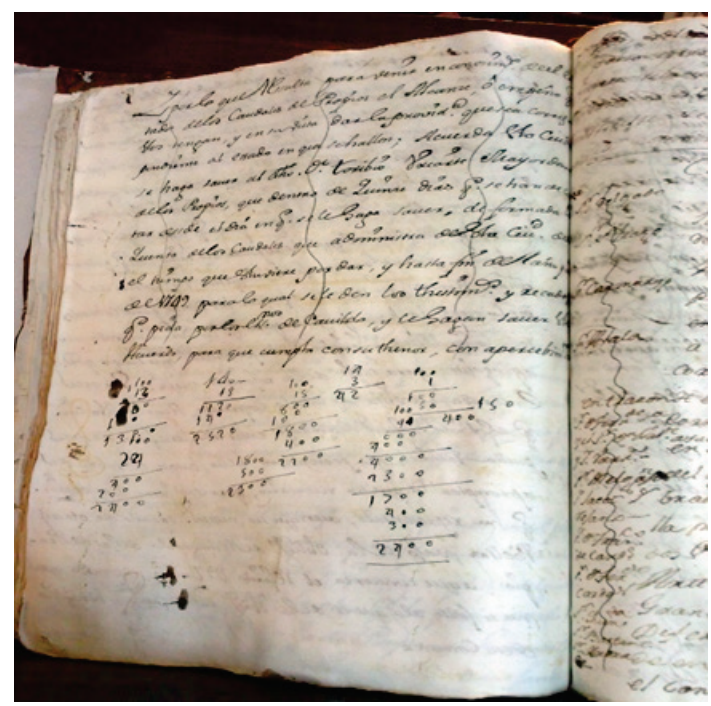

Figura 1. A. M. M., AA. CC., año 1750, s. f.

Del cabildo malagueño dependían los sueldos tanto de los escribanos del concejo, como de sus oficiales y archivistas, tal y como ya se ha mencionado. A los primeros, además de su salario, se les daba un montante anual fijo para el gasto de papel sellado y de encuadernación de los libros que redactaban. El papel sellado era de vital importancia ya que por ley todo documento que se redactara en el cabildo por parte de su escribano tenía que estar elaborado sobre dicho papel. No obstante, hemos localizado ejemplos donde el papel sellado fue insuficiente, por lo que el propio escribano o su oficial escribía de su puño y letra el sello; esto sucedía bien porque no se hubiera precisado correctamente la cantidad de papel necesario, o bien porque el cabildo no dispusiera del dinero suficiente para hacer frente durante un período de tiempo del gasto que conllevaba la compra de papel sellado.

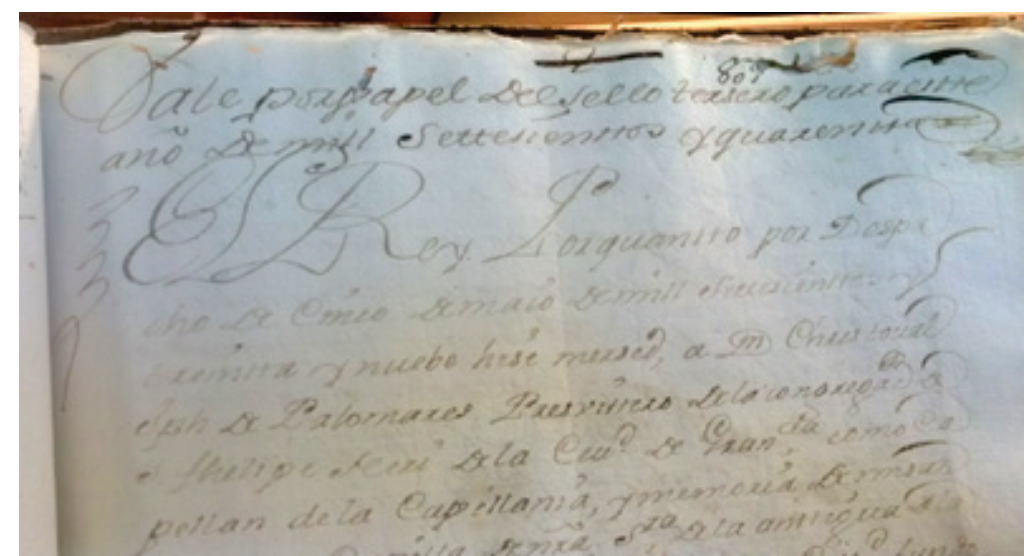




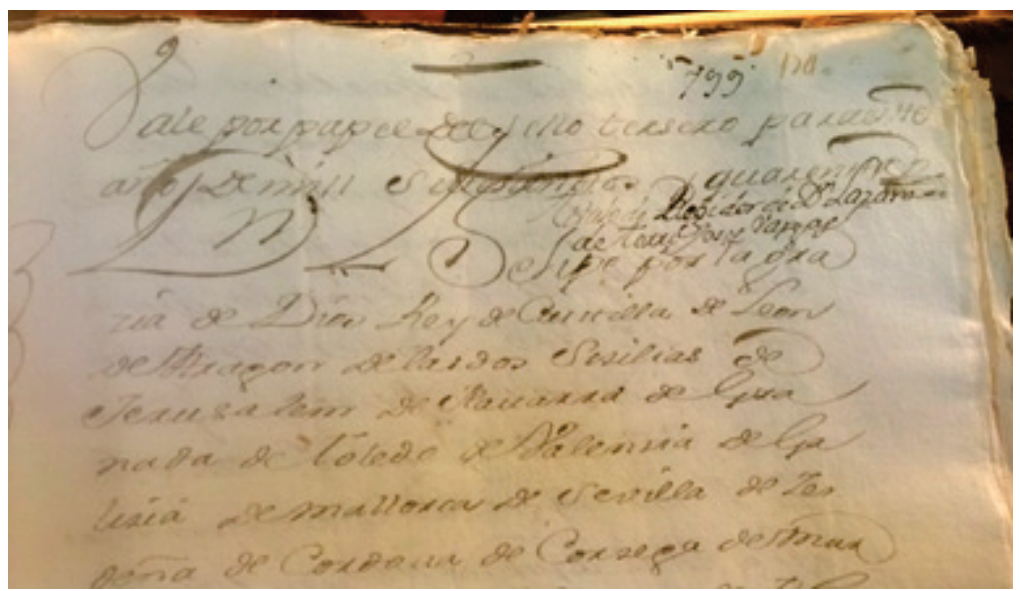

Figuras 2 y 3. Ejemplos de falta de papel sellado en el cabildo malagueño. A. M. M. Libro de Reales Provisiones, Vol. 88, fs. 799r y 801r.

El cabildo liberaba de las rentas de propios cuatrocientos reales de vellón anuales para el gasto de este papel sellado y para la encuadernación, montante que liberaba a favor del escribano mayor del concejo:

(...) La ciudad en sus renta de propios libro a Don Juan de Rute y Torre, escribano mayor de cauildo, quatrocientos reales vellón por el gasto del papel sellado y enquadernacion del libro capitular del año próximo pasado de sietescientos y trenta y nuebe. En la forma que esta acordado de que se despache libransa en forma, luego que conste auer puesto el expresado libro capitular en el archiuo donde debe parar. De que tome rason el contador $(\ldots)^{45}$.

Como podemos comprobar, el gasto de la encuadernación solo hace referencia al libro capitular, nada se menciona sobre los demás libros o legajos de los que también se encargaba el escribano de cabildo. Además, podemos sustraer información sobre la custodia y preservación de la documentación, donde ya se tiene consciencia de la importancia de la conservación de los documentos para preservar los derechos de la ciudad y sus habitantes. Por lo que existía un archivo en el concejo municipal, donde además había dos personas ${ }^{46}$ a su cargo, que para el año de 1740 eran Francisco de Amat y Francisco Carmargo ${ }^{47}$, los cuales eran los encargados de velar por la seguridad y mantenimiento del archivo y sus papeles tal y como dice la propia documentación.

Se tiene constancia de una escribanía de cabildo denominada como de ausencias y enfermedades, es decir, se nombraba a un fedatario para que supliera a aquellos escribanos de cabildo cuando estos se encontrasen ausentes de la ciudad, o bien impedidos por algún tipo de enfermedad. Es lo que sucedió en una de las escribanías

45 A. M. M., AA. CC., Vol. 132, f. 11v.

46 Nombrados según la documentación como dos diputados de archivo. A.M.M., AA. CC., Vol. 132, f. 13v.

47 Ibídem. 
de cabildo de la capital malagueña, donde Juan de Rute, escribano del concejo malagueño, no podía atender sus labores, por lo que se nombró a un escribano interino en ausencia de aquel. Este escribano interino fue Francisco Joseph González Nieto, por un período de tres años. Cuando en 1751 falleció el otro escribano de cabildo, Antonio Calvo, la ciudad reunida acordó que el escribano interino había dado muestras de un buen trabajo y decidió nombrarlo ya como escribano mayor de cabildo y no como interino:

(...) lo mucho que don Francisco Joseph Gonzales Nieto ha seruido de muchos años ha esta parte y a los señores gobernadores inteligencia y caridad con todo clase de pobres y que lo mismo hauia ejecutado de tres años que ha que le nombro por escriuano de cauildo en ausencias y enfermedades de los propietarios. Atendiendo la ciudad a estos justificados motivos y hauer quedado bacante la rreferida escriuania de cauildo por el fallecimiento de don Antonio Calbo. De un acuerdo y conformidad de todos los caualleros rexidores presente y em virtud de la real facultad que para ello tiene, nombro por tal escriuano de cauildo y publico a ella agregada del numero, a el expresado don Franciscro Joseph Gonzalez Nieto $(. . .)^{48}$.

El año de 1751 fue de trágicas noticias para los escribanos del cabildo malagueño. Primero falleció Antonio Calvo, tal y como se apuntara más arriba, y se nombró en su lugar al escribano que había estado sirviendo la escribanía de Juan de Rute y Torre, ya que este al encontrarse enfermo no podía atenderla. Y transcurridos apenas unos meses, en mayo de ese mismo año, fallecía el mencionado Juan de Rute y Torre, por lo que de nuevo el cabildo malagueño se vio en la necesidad de nombrar a un nuevo escribano para atender las necesidades del concejo malacitano. Para ocupar dicha escribanía concurrieron a ella varias personalidades, presentando cada uno de ellos sendos memoriales. Los que aspiraban a ella eran Juan Joaquín de Marmolejo, Dionisio López Cuartero, Pedro Páez, Pedro de Rivera, Joseph de Lucena y Antonio Paredes $^{49}$. Menos este último que era oficial de la escribanía de cabildo, los demás eran todos escribanos numerarios. El procedimiento era el habitual en estos casos, votar en sesión capitular a los que optaban a desempeñar el cargo. Una vez votados, el que mayor número de votos obtuvo fue Dionisio López Cuartero, con ocho, seguido de Antonio Paredes con cinco y Pedro de Ribera con uno ${ }^{50}$.

En este caso podemos apreciar cómo uno de los requisitos necesarios para ser escribano de cabildo en Málaga a veces podía pasarse por alto. Nos referimos a la necesidad de ser escribano numerario para poder optar y servir uno de los escritorios del cabildo malacitano. En 1751 Antonio Paredes, oficial de una de las dos escribanías mayores del cabildo malagueño, pudo alzarse como escribano del mencionado ayuntamiento ya que su candidatura fue tenida en cuenta y votada, además quedó en segundo lugar. Ello nos indicaría que, aunque por norma general el escribano de cabildo salía de uno numerario tal y como indicaba la ley, podía darse el caso de que esta obligación no fuera tenida en cuenta. Lo que es sintomático de que en realidad

48 A. M. M., AA. CC., Vol. 142, fs. 70r-71r.

49 Para saber más de esta figura y de los oficiales de pluma ver L. BARCO CEBRIÁN, "Análisis de un colectivo socio-profesional minusvalorado: los oficiales de pluma en la España meridional según el Catastro de Ensenada", en Documenta \& Instrumenta, 14 (2016), pp. 17-31.

50 A. M. M., AA. CC., Vol. 142, fs. $116 \mathrm{v}-117 \mathrm{v}$. 
dentro de la institución notarial las obligaciones eran tomadas con una cierta laxitud por parte de sus integrantes, más si cabe en el caso de las escribanías de concejo, ya que eran los integrantes de aquel los encargados de nombrar a sendos fedatarios. Por lo tanto, entrarían en juego otras muchas consideraciones, no solo familiares o económicas, sino también de afectividad tal y como pudieron ser los votos a Antonio Paredes, quien llevaba trabajando como tal oficial desde hacía varios años, lo que sin lugar a dudas le brindaría cierto sentimiento de amistad y afinidad con los miembros integrantes del cabildo malagueño. El memorial que este último presentó al cabildo para que se le tuviera en consideración en los votos emitidos para nombrar a un nuevo escribano del conejo fue el siguiente:

Yllustrisima ciudad, Don Antonio Paredes y Aguilar, vecino de esta ciudad y oficial maior actual de una de las escriuanias de ayuntamiento de vuestra señoría. Puesto a su obediencia con la mas profunda y deuida veneracion: Dice que hauiendo logrado el suplicante el honor de hauer estado siruiendo a vuestra señoria de oficial maior en la que ejercio Don Antonio Caluo tiempo de dies años, y los inisios de procurador de vuestra señoria, para la defensa, seguimiento de sus dependencias y pleitos, en cuio seruicio a procurado con el maior exsemero desempañar su obligación como asi consta a vuestra señoria. Y en particular a los caualleros, procuradores generales que han seido en el presitado tiempo y con el motiuo de hauer fallecido don Juan de Rute y Torre, escriuano de su ayuntamiento, suplica rendidamente a vuestra señoria, que en atención a los expresados seruicios se sirua conferirle el nombramiento de dicha escriuania para que en ella y en lo demas que ocurre pueda el suplicante seruir a vuestra señoria, con el desuelo que siempre ha solicitado cuio fauor espera reseuir de la piadosa justificación de vuestra señoria. A quien nuestro señor propere dilatada años en su maior grandesa. Antonio Paredes y Aguilar ${ }^{51}$.

Si analizamos la escritura presentada para que se tome en consideración la candidatura del susodicho Antonio Paredes, y la comparamos con el resto de las candidaturas, siguen todas un mismo modelo y estructura. Siempre se dirige a la ciudad, se presenta el nombre del candidato y se expresa la voluntad de obtener el oficio y el porqué, es decir, su experiencia laboral que acredite que está capacitado para desempeñar el cargo al que se presenta.

\section{Conclusión}

Efectivamente, el ser escribano de cabildo o ayuntamiento era un puesto codiciado. Esto se debía primero a que al servir dicho escritorio el fedatario se involucraba de lleno en la vida pública y política de la ciudad, codeándose con las élites locales, lo que favorecería su posición dentro de la sociedad. Y, segundo, porque el servir dicho puesto le conllevaba una mejora salarial y económica, ya que se les remuneraba con un montante anual fijo, lo que no se daba en las escribanías numerarias. Por lo tanto, era un beneficio social, económico y les daba una cierta tranquilidad salarial a aquellos que finalmente se hacían con una escribanía de cabildo. Pero no todo eran beneficios, ya que muchas veces la ciudad no podía hacer frente a todos los gastos que

51 A. M. M., AA. CC., Vol. 142, fs. 123r-v. 
conllevaba el mantener los escritorios, no solo los salarios de los escribanos mayores, sino tampoco correr con los gastos del papel sellado, archivistas u oficiales de las escribanías. Esto conllevaba pleitos entre los escribanos y sus oficiales con el cabildo $\mathrm{y}$, además, se aprecia una desidia en los quehaceres de estos fedatarios y oficiales, que tal y como se ha podido comprobar consistía en la no firma de las diferentes sesiones capitulares, la no organización del archivo y la no encuadernación de los fondos documentales. Todo ello también dará lugar a enfrentamientos entre sendos colectivos ya mencionados. No obstante, en un cómputo global se puede concluir que eran más los beneficios que se daban al hacerse con una escribanía del cabildo que los hándicaps.

\section{Apéndice documental}

\begin{tabular}{|c|c|}
\hline ESCRIBANO & LUGAR \\
\hline Juan de Rojas Sandoval & Escribano público de Alfarnate y Alfarnatejo. \\
\hline $\begin{array}{l}\text { Marcos Joseph } \\
\text { Domínguez }\end{array}$ & $\begin{array}{l}\text { Escribano de cabildo, público y rentas de Alhaurín de la Torre. } \\
\text { Escribano público y de ayuntamiento de Churriana. }\end{array}$ \\
\hline Manuel de Bustanovi & $\begin{array}{l}\text { Escribano de ayuntamiento de Almáchar. } \\
\text { Escribano de rentas de El Borge. }\end{array}$ \\
\hline Cristóbal Moraga & $\begin{array}{l}\text { Escribano del concejo de Almogía. } \\
\text { Escribano del número de Málaga. }\end{array}$ \\
\hline Gerónimo Velasco & Escribano público, de millones y cientos de Antequera. \\
\hline Joseph León Granadino & $\begin{array}{l}\text { Escribano de fechos de Arenas del Rey. } \\
\text { Escribano público de Málaga. }\end{array}$ \\
\hline Lucas Pastor & $\begin{array}{l}\text { Escribano público y de cabildo de Banalauría. } \\
\text { Escribano público y de cabildo de Benadalid. }\end{array}$ \\
\hline $\begin{array}{l}\text { Pascual Dionisio } \\
\text { Criado }\end{array}$ & $\begin{array}{l}\text { Escribano de cabildo de Benamargosa. } \\
\text { Escribano de cabildo y público de El Borge. } \\
\text { Escribano público de Cutar. }\end{array}$ \\
\hline $\begin{array}{l}\text { Juan Félix de } \\
\text { Villaluenga }\end{array}$ & $\begin{array}{l}\text { Escribano público y de cabildo de Benamargosa. } \\
\text { Escribano público de cabildo de Iznate. }\end{array}$ \\
\hline Vicente Palmero & $\begin{array}{l}\text { Escribano público y de concejo de Benaoján. } \\
\text { Escribano público y de concejo de Montejaque. }\end{array}$ \\
\hline $\begin{array}{l}\text { Francisco Antonio } \\
\text { Coronado }\end{array}$ & $\begin{array}{l}\text { Escribano público y de concejo de Benaque. } \\
\text { Escribano público y de concejo de Macharaviaya. } \\
\text { Escribano de fechos de Moclinejo. }\end{array}$ \\
\hline Juan Basilio Pabón & $\begin{array}{l}\text { Escribano de Canillas de Albaida. } \\
\text { Escribano público y de concejo de Cómpeta. } \\
\text { Escribano de concejo de Salares. }\end{array}$ \\
\hline Juan García de Lara & $\begin{array}{l}\text { Escribano de fechos de Corumbela. } \\
\text { Escribano de fechos de Sayalonga. }\end{array}$ \\
\hline $\begin{array}{l}\text { Antonio Marcos } \\
\text { González }\end{array}$ & $\begin{array}{l}\text { Escribano público y de concejo de Gaucín. } \\
\text { Escribano público y de concejo de Benamaya. }\end{array}$ \\
\hline Francisco Pérez Pardo & Escribano de Monda y Tolox. \\
\hline Antonio Guirado & $\begin{array}{l}\text { Escribano de Arenas. } \\
\text { Escribano público y de concejo de Daimalos. }\end{array}$ \\
\hline
\end{tabular}

Fedatarios de la provincia de Málaga que sirven varios escritorios a mediados del s. XVIII. 


\section{Documento $1^{52}$}

Conocimiento del fallecimiento del escribano mayor de cabildo de Málaga Antonio Calvo y de su oficial mayor, Antonio Paredes y Aguilar. Nombramiento de dos escribanos públicos para el examen del trabajo de los mencionados Antonio Calvo y Antonio Paredes.

Archivo Municipal de Málaga, Actas Capitulares, Vol. 141, fs. 1r-2r, año 1750.

Don Francisco Camargo Mondragon, vecino rexidor perpetuo y procurador general de esta yllustrisima ciudad, ante Vuestra Merced, como mas haya lugar en derecho y sin perjuicio de otra (...) de mi parte competo. Paresco y digo que auiendo muerto este presente año Don Antonio Caluo, escriuano que era de cauildo, y a cuyo cargo estubo la exzecucion de todos los celebrados el año proximo pasado y autorizarlos por que fue el que los presensio, se encuentran muchos de dichos acuerdos sin auerlos firmado, aunque si escrito todos a el parecer en el libro capitular, y lo mismo los borradores de dichos acuerdos letra y mano de Don Antonio Paredes, que tambien en este presente año ha muerto como oficial mayor que era del dicho Don Antonio Caluo. En fuerza de lo qual y para en el modo posible verificar dicha realidad Suplico a Vuestra Merced se sirua mandar que personas que tenia conocimiento de la letra del dicho Don Antonio Paredes vean la letra de dichos acuerdos tanto en los vorradores como en limpio y declaren si toda ella segun su conocimiento es sierta de mano del dicho Don Antonio Paredes, y la misma que acostumbraua escriuir. Y asi ejecutado, mandar llamar a cauildo con especial encargo de que concurran todos los caualleros regidores para con la asistencia de Vuestra Merced, deliuerar lo que mas combenga para remediar dicho cauildo, que asi procede de justicia que pido y para ello [roto] y juro y protesto lo nesesario.

Francisco Camargo Mondragon (rúbrica).

Licenciado don Bernardo Aluerto de Olivera y Torres (rúbrica).

Don Dionisio Lopez Quarttero y Hermenegildo Ruiz, escribanos publicos de este numero, aquienes su merced nombra como yntelixentes y personas que tubieron conocimiento de la letra de don Antonio Paredes, hagan el reconocimiento que se pide. El que comparescan a declarar, y fecho autos lo mando el señor Don Juan Miguel Diez, Abogado de los Reales Conzejos, Alcalde mayor en esta ciudad de Malaga.

52 Las normas de transcripción que se han seguido se ajustan a los siguientes puntos: para que el lector pueda acceder a una lectura fácil y comprensiva se han desarrollado todas las abreviaturas encontradas y se ha adecuado el texto a las normas de puntuación actuales. Se respeta la ortografía del texto original, salvo en los casos que se especifican a continuación. La transcripción se realiza siempre a línea tirada, sin separación de renglones. Las palabras unidas irregularmente se han separado, del mismo modo, aquellas que se encuentra separadas de forma errónea se han unido. La " $u$ " y la "v" que tenían indistintamente en algunas ocasiones valores vocálicos y consonánticos, se han mantenido tal y como aparecen en el texto original. Cuando aparece alguna anomalía en el texto que se debe a la pluma del escribano, tal como falta de copia, salto gráfico, repeticiones de sílabas o palabras, se transcribe tal y como aparece en el texto original indicándolo a través del adverbio latino "sic" entre paréntesis y en cursiva. Las letras, palabras o frases que nos encontramos entre renglones se han transcrito entre corchetes angulares. Cuando en el soporte escriturario se encuentra un roto y el cuerpo de texto es irrecuperable se indica con tres puntos suspensivos entre paréntesis. Los espacios en blanco encontrados en los documentos se indican entre paréntesis y en cursiva, ej. (blanco). Si alguna letra, sílaba, palabra o palabras no se ven por mancha o deterioro del soporte escriturario, pero se puede leer por el contexto, se indica entre corchetes. A las dudas sobre algunas de las palabras transcritas, ya sea por abreviaturas dudosas o inusuales, o bien por alguna voz extraña, se añade un signo de interrogación entre paréntesis. Las normas aquí planteadas se han seguido conforme a las establecidas por Agustín Millares Carlo en su obra Tratado de Paleografia Española, Espasa

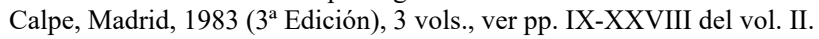


En ella, en diez y seis dias en el mes de junio de mill setezientos cinquenta y dos años. Diez (rúbrica).

Antonio de Amorin y Diaz, escribano (rúbrica).

En Malaga, en este dicho dia, mes y año yo, el escribano, hize saver el contenido del auto que antesede y nombramiento que por el se hase a don Hermenegildo Ruiz y don Dionisio Lopez Quartero, escribanos publicos de este numero, quienes enterados dijeron lo aseptaban y aseptaron y juraron en toda forma a ser su deuer, y este respondieron y firmaron de que doy fee. Hermenegildo Ruis, escribano publico (rúbrica).

Don Dionisio Lopes Quartero (rúbrica).

Antonio de Amorin y Diaz, escribano publico (rúbrica).

\section{Documento 2}

Resultados del examen de los documentos de Antonio Calvo y Antonio Paredes por parte de Hermenegildo Ruiz y Dionisio López Cuartero.

Archivo Municipal de Málaga, Actas Capitulares, Vol. 142, fs. 2r-4r, año 1751.

En la ciudad de Malaga, en nuebe dias del mes de jullio de mill setezientos cinquenta y un años, el señor don Juan Miguel Diez, abogado de los Reales consejos, alcalde mayor y correjidor interino de esta dicha ciudad, por antemi el escribano resiuio juramento a Dios y una cruz, según forma de derecho, de don Hermenegildo Ruis y Don Dionisio Lopez Quartero, vecinos de esta ciudad y escribanos de su numero, que lo hicieron y a cargo del prometieron la verdad, y preguntados por el pedimento que antesede enterados dijeron que en fuerza del nombramiento que les a sido echo y tienen aceptado, y en caso nesesario de nuevo, aceptan, an visto el libro capitular del año pasado, de setezientos y cinquenta, cavildo por cauildo, el que se conpone de veynte y nuebe quadernos, y en el primero solo enquentran allarse por autorizar de escribano la copia de una carta orden del yllustrisimo señor obbispo de Barzelona, Governador del Real consejo de Castilla, sobre pretencion que hizo don Pedro Bohurman, Rejidor perpetuo de esta ciudad, de que se le tubiese presente en el cauildo de suertes, no obstante no a ver asistido a los treynta y tres por a ver estado acidentado.

Y, desde este quaderno ynclusibe hasta el veynte y dos, se hallan los cauildos que paresen en ellos celebrados corrientes de formas, ezepto el quinto, un decimo, decimo tercio, decimo quarto y decimo octavo, que en estos faltan seis firmas del señor Alcalde mayor, y tambien en el mencionado veynte y dos se encuentra por autorisar la copia de un despacho del Real consejo de Asienda sobre la contribucion de los derechos de alcaualas, de segundas ventas.

En el quaderno veynte y cinco se hallan seis cavildos y todos ellos por firmar del señor juez, que los precidio. El quaderno veynte y seis todos los cauildos que del constan se hallan sin firmas del señor jues, cuallero capitular y escribano. El quaderno veynte y seite se halla con el mismo defecto y tanbien el de no estar autorizada la copia de un real despacho del consejo de Castilla, por el que se aprueba la transaccion echa por esta ciudad y don Dionisio Cauello sobre la propiedad del cortijo y tierras del Almendral del Rey.

Los quadernos veynte y ocho y veynte y nuebe contienen el mismo defecto de firmas que los antesedentes. 
Y, por lo que respecta a las letras, asi, de dicho libro capitular como del Borrador, según su conocimiento, es la letra de don Antonio Paredes, oficial mayor que fue en la escribania mayor de cauildo, que ejercio don Anttonio Calbo, auiendo visto la una y otra parese ser toda del mencionado Paredes a ezepcion de los cauildos que se hallan en dicho borrador desde el treynta y uno de agosto hasta el dose de octubre de dicho año pasado, que la letra de estos parese ser de don Pedro Cano, oficial menor de dicha escribanía.

Que es lo que según su ynteligencia pueden desir y la verdad cargo de su juramento que fecho lleuan y que son dudas. Don Hermenegildo Ruis, de quarenta años, y el espresado don Dionisio Quartero, de quarenta y cinco, lo firmaron, y dicho señor corregidor.

De todo lo qual yo, el escribano, doy fee.

Diez (rúbrica).

Don Dionisio Lopez Quartero (rúbrica).

Hermenegildo Ruiz, escribano publico (rúbrica).

Antonio de Amorin y Diaz, escribano publico (rúbrica).

Don Dionicio Lopez Quartero, escribano publico del numero desta ziudad y su auintamiento, zertifico y doi fee que en el que esta ziudad celebro oy dia de la fecha publica el que fue zitado de orden del señor alcalde mayor a todos los caualleros rexidores para en el ver lo dicho por los escribanos nombrados por el señor alcalde mayor para reconozimiento del libro capitual del año antezedente de seteziento y zinquenta, que algunos quadernos de el se hallan sin firmar, por el fallecimiento de don Antonio Caluo, y si contextan con los borradores. Dieron fee los porteros auer hecho dicha citasion a todos los caualleros rexidores, ezepto enfermos y ausente en el, se hizo presente y leio un pedimiento dado por el señor don Francisco Camargo, procurador general, por el que expresa que por el fallezimiento de don Antonio Caluo, escribano que fue deste auintamiento, y a cuio cargo estubo la extecion de todos los celebrados en dicho año, se encuentran muchos de dichos acuerdos sin auerlos firmado, aunque escrito todos al parezer en el libro capitular, y lo mismo los borradores de dichos acuerdos de letra y mano de don Antonio Paredes, oficial que fue de dicho don Antonio, para que personas intelixentes reconoscan la letra de dichos acuerdos, si es la del dicho don Antonio Paredes y los borradores.

Y por el señor Alcalde mayor se mando assi y nombro para ello a don Hermenejildo Ruiz y don Dionisio Lopez Quartero, quienes lo aceptaron. Y en el dia nuebe de jullio antezedente, auiendo hecho el reconoziemitno de dicho libro capitular y los borradores de el, según la practica que tienen en letras, declararon ser de pluma y letra, assi el apitular como los borradores del expresado Paredes, como tal oficial mayor que fue de dicho oficio (que tambien murio).

La ziudad entendida, acordo que para que tenga validacion en lo posible los cauildos que se notan defectuosos de firmar por defecto del escribano, ante quien pasaron de no auerlos lleuado a su deuido tiempo a las firmas de los señores Juezes y caualleros capitulares mediante a que por las dilixencias ultimamente practicadas a instancia del cauallero procurador general, estando todos citados acuerdos que se notan defectuosos comformes y arreglados a las minutas de los borradores y aquellos escritos en limpio de letra de don Antonio Paredes, oficial mayor que a la sason (...) del oficio de este cauildo de cargo de don Antonio Calvo, defunto uno y otro de entera fee, legalidad y credicto, se firmen desde luego dichos cauildos que no lo estan 
por el señor correxidor y de los señores capitulares que respectiuamente a ellos concurrieron, poniendo a la margen de cada uno de los citados cauildos la nota correspondiente de auer sido firmado en fuerza del presente. La qual dicha nota firmara el presente escribano y rubricara dicho cauallero capitular y señor correxidor, y el dicho libro capitular que va zitado se agregara el pedimento y dilixencias a su continuacion, practicadas con el borrador que tambien devera rubricarse y testimonio deste acuerdo. Como lo relasionado mas por esstenso consta de dicho cauildo en el libro capitular deste año a que me remito.

Malaga, veinte y siete de agosto de mil seteciento y zinquenta y uno.

Don Dionisio Lopez Quartero (rúbrica). 